\title{
Separation of cobalt and nickel with a thermomorphic ionic-liquid-based aqueous biphasic system
}

Received 00th January 20xx, Accepted 00th January 20xx

DOI: $10.1039 / \times 0 \times x 00000 x$

\author{
Bieke Onghena, ${ }^{a}$ Tomas Opsomer $^{\mathrm{a}}$ and Koen Binnemans ${ }^{\mathrm{a} *}$
}

www.rsc.org/

The $\left[\mathrm{P}_{44414}\right][\mathrm{Cl}]-\mathrm{NaCl}-\mathrm{H}_{2} \mathrm{O}$ ionic liquid-based aqueous biphasic system shows promising results for the separation of cobalt(II) and nickel(II) with homogeneous liquid-liquid extraction. The extracting phase exists of a hydrophilic ionic liquid that is salted-out by sodium chloride, indicating that there is no need for using hydrophobic ionic liquids.

Recent advances in sustainable hydrometallurgical processing of metals focus on the use of hydrophobic ionic liquids (ILs) for separations of metal ions by solvent extraction. ${ }^{1-4}$ Ionic liquids are solvents that consist entirely of ions. Because of their low flammability and low volatility, ILs are considered to be safer and more environmentally friendly than the traditional diluents that are currently used in industry, such as kerosene. ${ }^{4-7}$ The main disadvantage of using ILs in solvent extraction is their high viscosity, which slows down the mass transfer during extraction and complicates the implementation of the IL solvent extraction processes on an industrial scale. ${ }^{8}$ Recently, our group applied the concept of homogeneous liquid-liquid extraction (HLLE) to ionic liquids as an answer to the slow mass transfer caused by the high viscosities of ILs. HLLE makes use of thermomorphic ILs, i.e. ILs that show temperature-dependent phase behavior in contact with water. ${ }^{9-11}$ Reversible conversion of the biphasic mixture to a homogeneous mixture by changing the temperature, causes the extraction equilibrium to be reached faster than by strong agitation of a biphasic mixture. Until now, mainly fluorine-containing ILs were successfully applied to the HLLE of metal ions. ${ }^{12-14}$ On the other hand, ILs with fluorine-free anions offer several advantages such as a lower price and less issues with toxicity and persistency in natural environments. ${ }^{15,16}$ Fluorine-free hydrophobic ILs, such as trihexyl(tetradecyl)phosphonium chloride (Cyphos IL 101), have already been used in solvent extraction processes, but these ILs

\footnotetext{
a. KU Leuven, Department of Chemistry, Celestijnenlaan 200F PO box 2404, 3001 Heverlee (Leuven), Belgium.Email: Koen.Binnemans@chem.kuleuven.be

Electronic Supplementary Information (ESI) available: Experimental information, orthogonal ternary phase diagram of the $\left[\mathrm{P}_{44414}\right][\mathrm{Cl}]-\mathrm{NaCl}-\mathrm{H}_{2} \mathrm{O}$ system and
} quantitative ${ }^{1} \mathrm{NMR}$ spectrum. See DOI: 10.1039/x0xx00000x generally do not show thermomorphic behavior with water and hence cannot be used in HLLE. ${ }^{13}, 20-28$ Furthermore, they have a high viscosity, which makes their application to industrial solvent extraction less straightforward.

In this Communication, the assets of both HLLE and fluorinefree ILs for the separation of metal ions are combined by using thermomorphic ionic liquid-salt aqueous biphasic systems (IL$A B S$ ) in HLLE. An IL-ABS usually consists of three components: (1) water; (2) a hydrophilic IL, preferably with fluorine-free cations; and (3) a salting-out agent, usually an inorganic salt. The salting-out agent causes the IL to phase separate from the mixture and a biphasic system is created. ${ }^{17-19}$ Phase separation is thus a composition-induced process (CIPS, compositioninduced phase separation). At certain mass compositions, many of the IL-ABS can also undergo temperature-induced phase separation (TIPS), thus they can be considered thermomorphic and applicable to HLLE. 17,20,21 Despite the advantages, few examples of the use of IL-ABS systems for the extraction of metal ions have been reported in the literature. Furthermore, the thermomorphic behavior has not been exploited yet. ${ }^{18,22-25}$ Here, the concept of using IL-ABS-HLLE for the separation of metals was applied to the separation of cobalt(II) and nickel(II) using the hydrophilic IL tributyl(tetradecyl)phosphonium chloride, $\left[\mathrm{P}_{44414}\right][\mathrm{Cl}]$, combined with $\mathrm{NaCl}$ as the salting-out agent. $\mathrm{NaCl}$ was selected for several reasons: (1) $\mathrm{NaCl}$ is cheap and easily available with a low impact on the environment; (2) it is a relatively good salting-out agent; and (3) the addition of chloride ions enhances extraction of anionic metal chloro complexes to the IL phase. ${ }^{26,27}$ Extraction with $\left[\mathrm{P}_{44414}\right][\mathrm{Cl}]$ behaves similar to Cyphos IL 101 since both ILs are anionic extractants, which means that they only extract metal ions in their anionic form, such as anionic tetrachloro cobaltate(II). 27,28 To examine the possibility of using $\left[\mathrm{P}_{44414}\right][\mathrm{Cl}]$ in an IL-ABS-HLLE system, the phase behavior and phase separation were first investigated as a function of the temperature and the $\mathrm{NaCl}$ concentration. By cloud point titration at room temperature, the concentration of $\mathrm{NaCl}$ required to induce phase separation was determined for different IL concentrations (expressed in 
wt\%) (Figure S1 in ESI). The cloud-point composition, i.e. the composition at which the homogeneous mixture becomes cloudy, was determined by titrating an aqueous solution of $\mathrm{NaCl}$ to an aqueous solution of the IL under constant stirring until a cloudy solution was detected visually. On the basis of these results, it was decided to carry out further experiments with mixtures always containing 40 wt\% of IL. In this way, the required amount of $\mathrm{NaCl}$ to obtain phase separation at room temperature was still limited (around $5 \mathrm{wt} \%$, Figure S1 in ESI) and the mass phase ratio of the biphasic mixture was around 1:1. A complete overview of the experimental methods and materials is given in the supporting information.

Preliminary heating and cooling tests revealed that $\left[\mathrm{P}_{44414}\right][\mathrm{Cl}]-\mathrm{NaCl}-\mathrm{H}_{2} \mathrm{O}$ showed a lower critical solution temperature (LCST) phase behavior in water, which implies that a biphasic mixture becomes homogeneous by cooling below a certain temperature. The temperature at which this phase transition occurs can be approximated by the cloud point temperature, which is literally the temperature at which a homogeneous mixture becomes cloudy at a specific composition, thus indicating a phase transition. The cloud point temperature of $\left[\mathrm{P}_{44414}\right][\mathrm{Cl}]-\mathrm{NaCl}-\mathrm{H}_{2} \mathrm{O}$ was determined at different $\mathrm{NaCl}$ concentrations, expressed in wt\% (Figure 1). The results show that by changing the $\mathrm{NaCl}$ concentration the system parameters can be tuned very easily to optimize the process, which is interesting for the application in HLLE. Note that at $\mathrm{NaCl}$ concentrations above $11 \mathrm{wt} \%$, the mixture cannot become homogeneous by cooling since the cloud point temperature is below the melting point of water. This implies that HLLE with a mixture containing 40 wt\% of $\left[\mathrm{P}_{44414}\right][\mathrm{Cl}]$ in total, is only possible at $\mathrm{NaCl}$ concentrations lower than $11 \mathrm{wt} \%$.

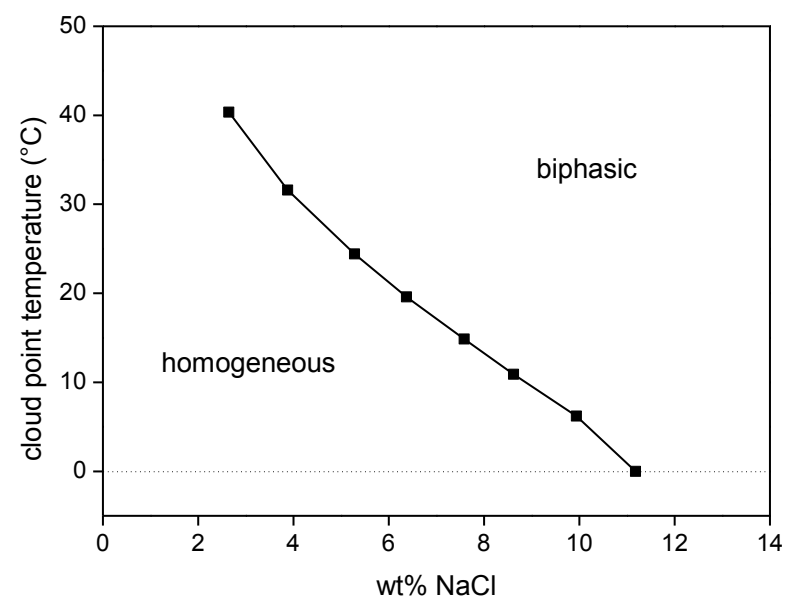

Figure 1. Influence of the $\mathrm{NaCl}$ concentration on the cloud point temperature of a $40 \mathrm{wt} \%$ solution of $\left[\mathrm{P}_{44414}\right][\mathrm{Cl}]$ in water.

Next, the $\left[\mathrm{P}_{44414}\right][\mathrm{Cl}]-\mathrm{NaCl}-\mathrm{H}_{2} \mathrm{O}$ system was applied to the separation of $\mathrm{Co}(\mathrm{II})$ and $\mathrm{Ni}$ (II) from chloride solution with HLLE. The separation of $\mathrm{Co}(\mathrm{II})$ and $\mathrm{Ni}$ (II) was chosen because it is an important, but challenging hydrometallurgical process step in the production of cobalt materials. ${ }^{29}$ Futhermore, they are known to be efficiently separated by traditional solvent extraction with quaternary phosphonium and ammonium ILs, but the high viscosity remains a challenge in these systems. ${ }^{8,27}$ The extraction and separation of $\mathrm{Co}(\mathrm{II})$ and $\mathrm{Ni}(\mathrm{II})$ was tested as a function of the $\mathrm{NaCl}$ concentration (wt\%) in the mixture (Figure 2) and expressed using the distribution ratio $D$ and separation factor $\alpha_{N i}^{C o}$, defined by equations 1-2:

$$
\begin{gathered}
D=\frac{c_{I L}}{c_{a q}} \\
\alpha_{N i}^{C o}=\frac{D_{C o}}{D_{N i}}
\end{gathered}
$$

where $c_{a q}$ and $c_{I L}$ are the metal concentrations after extraction in the aqueous and IL-rich phase, respectively.
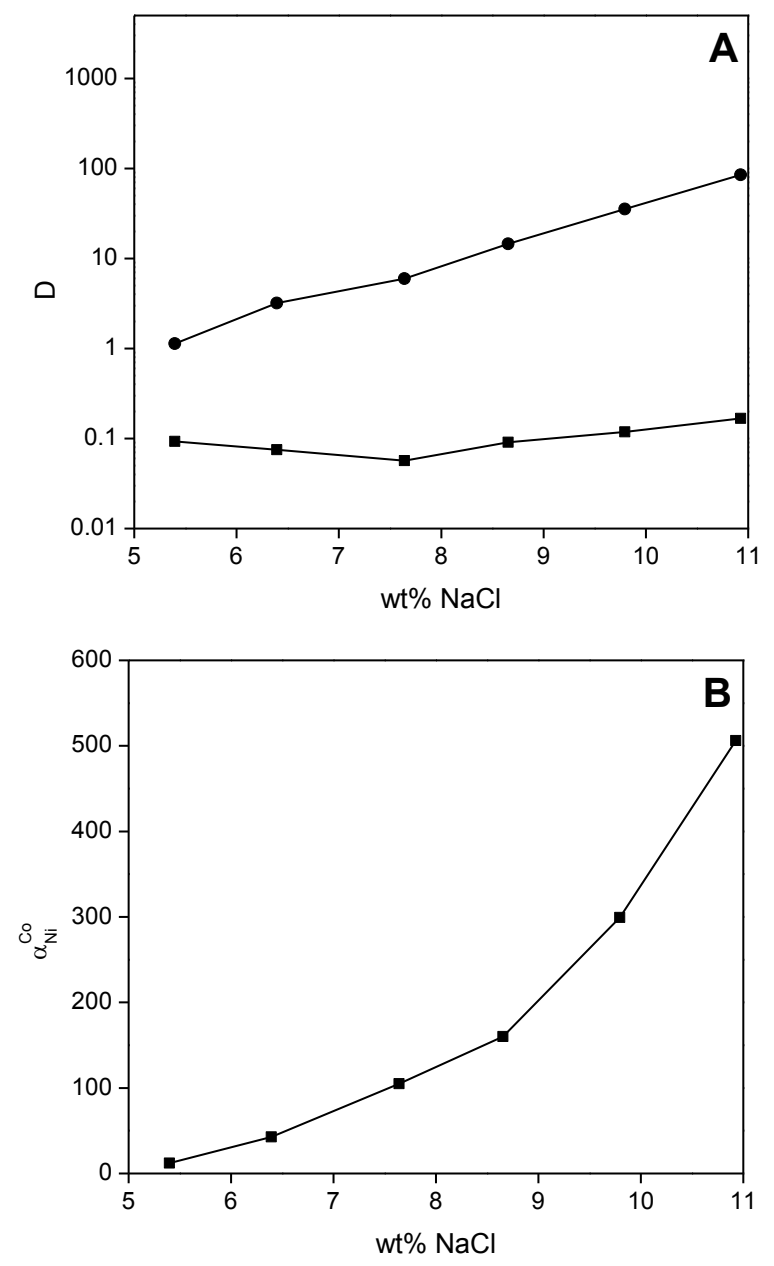

Figure 2. A: HLLE of $\mathrm{Ni}(\mathrm{II})$ (घ) and $\mathrm{Co}(\mathrm{II})(\bullet)$ from chloride solution as a function of the $\mathrm{NaCl}$ concentration (wt\%) in the extraction mixture, B: the corresponding separation factors

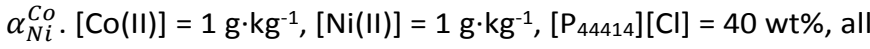
calculated over the entire mixture.

The results showed that $\mathrm{Ni}(\mathrm{II})$ was only poorly extracted to the IL-rich phase $(D \sim 0.1)$ and extraction was not improved by increasing the $\mathrm{NaCl}$ content in the mixture up to $11 \mathrm{wt} \%$. On the other hand, Co(II) was extracted much better, with $D$ values up to 100 at $11 \mathrm{wt} \% \mathrm{NaCl}$. This difference in extractability of $\mathrm{Ni}(\mathrm{II})$ and $\mathrm{Co}(\mathrm{II})$ at increasing $\mathrm{NaCl}$ concentration led to increasing separation factors up to 500 at $11 \mathrm{wt} \%$ of $\mathrm{NaCl}$. As expected, the 
selectivity of extraction to the IL-rich phase is in line with the results obtained by Wellens et al. on the Cyphos IL 101 system and can be explained by the fact that Co(II) easily forms extractable anionic chloride complexes, while Ni(II) does not, not even at high chloride concentrations. ${ }^{27}$ However, the distribution ratios obtained with the IL-ABS-HLLE system are slightly lower than with the Cyphos IL 101 system because of the higher water content in the IL-rich phase (Table 1).27,30 Presence of water in the IL rich phase results in more physical resemblance between both phases, thus lower preferential distribution to the IL-rich phase.

Table 1. Influence of the wt\% of $\mathrm{NaCl}$ in the $\left[\mathrm{P}_{44414}\right][\mathrm{Cl}]-\mathrm{NaCl}-\mathrm{H}_{2} \mathrm{O}$ ABS mixture on the water content in the IL-rich phase determined with Karl Fischer titration and comparison with water-saturated Cyphos IL 101.

\begin{tabular}{ccc}
\hline & $\begin{array}{c}\mathrm{NaCl} \text { content in } \\
\text { mixture } \\
\text { (wt\%) }\end{array}$ & $\begin{array}{c}\text { Water content } \\
\text { in IL-rich phase } \\
\text { (wt\%) }\end{array}$ \\
\hline & 5.4 & 24.8 \\
{$\left[\mathrm{P}_{44414}\right][\mathrm{Cl}]-\mathrm{NaCl}-\mathrm{H}_{2} \mathrm{O}$} & 7.6 & 19.2 \\
& 9.8 & 15.5 \\
Cyphos IL 101- $\mathrm{H}_{2} \mathrm{O}$ & 11.9 & 14.0 \\
& 13.1 & 12.9 \\
& - & $12.8^{a}$
\end{tabular}

$a$ literature value, water-saturated Cyphos IL $101^{30}$

${ }^{b}$ literature value, Cyphos IL 101 saturated with $8 \mathrm{M} \mathrm{HCl}^{27}$

The extraction of $\mathrm{Co}(\mathrm{II})$ and subsequent separation between $\mathrm{Co}(\mathrm{II})$ and $\mathrm{Ni}$ (II) was further improved by increasing the $\mathrm{NaCl}$ content in the mixture: $D_{\mathrm{Co}}=500$ and $\alpha_{N i}^{C o}=2500$ at $13 \mathrm{wt} \%$ $\mathrm{NaCl}$. But, these mixtures with a composition of $40 \mathrm{wt} \%$ $\left[\mathrm{P}_{44414}\right][\mathrm{Cl}]$ and more than $11 \mathrm{wt} \% \mathrm{NaCl}$ could no longer become homogeneous by changing the temperature, as also depicted in Figure 1. However, the separation between $\mathrm{Co}(\mathrm{II})$ and $\mathrm{Ni}$ (II) with HLLE could be improved by optimizing the composition of the extraction mixture to increase the amount of $\mathrm{NaCl}$ that can be added. As indicated before, the amount of $\mathrm{NaCl}$ needed to induce phase separation is higher at lower IL content in the mixture (Figure S1 in ESI). This also means that at a lower IL content in the mixture, the amount of $\mathrm{NaCl}$ that can be added to remain within the thermomorphic region is higher and higher separation factors $\alpha_{N i}^{C o}$ could be obtained.

With respect to reusability and losses of the IL during the extraction process, it is important to know the IL content in the aqueous phase after extraction, since this value must be as low as possible to prevent unwanted losses. Quantitative ${ }^{1} \mathrm{H}$ NMR measurements were made to determine the IL concentration in the aqueous phase of an extraction mixture containing $40 \mathrm{wt} \%$ $\left[\mathrm{P}_{44414}\right][\mathrm{Cl}], 5.4 \mathrm{wt} \% \mathrm{NaCl},[\mathrm{Co}(\mathrm{II})]=1 \mathrm{~g} \cdot \mathrm{kg}^{-1}$ and $[\mathrm{Ni}(\mathrm{II})]=1 \mathrm{~g} \cdot \mathrm{kg}$ 1. Phenol was added as internal standard, since the peak of its aromatic protons does not overlap with the resonances of water or the ionic liquid. ${ }^{31}$ The IL concentration was very low and close to the detection limit of the ${ }^{1} \mathrm{H}$ NMR measurement. By comparison with the peaks of phenol, the IL concentration was estimated to be below $0.2 \mathrm{wt} \%$. This is a much lower value than for instance for the HLLE system with [Hbet][Tf $\left.{ }_{2} \mathrm{~N}\right]$ (14 wt\%). ${ }^{10,11,32}$

Finally, the dynamic viscosity $\eta$ of the IL-rich phase after extraction was determined at room temperature $\left(22^{\circ} \mathrm{C}\right)$ as a function of the wt\% of $\mathrm{NaCl}$ in the mixture (Figure 3). It is evident that the viscosity of the IL-rich phase increases with increasing wt\% of $\mathrm{NaCl}$ in the mixture. This trend can be explained by two factors: (1) the increase in the extracted Co(II) concentration in the IL-rich phase causes an increase in viscosity due to the formation of a divalent anion, as was described by Vander Hoogerstraete et al., ${ }^{28}$ and (2) the decrease in water content of the IL-rich phase with increasing wt\% of $\mathrm{NaCl}$ (Table 1 ) also results in higher viscosities. The viscosities varied around $120 \mathrm{mPa} \cdot \mathrm{s}$ at $22^{\circ} \mathrm{C}$. These values are approximately 10 times lower than the viscosities reported on the water-saturated Cyphos IL 101 system, which is around $830 \mathrm{mPa} \cdot \mathrm{s}$ at room temperature. ${ }^{27,28}$ This clearly indicates that viscosity problems in the extraction process, i.e. slow kinetics due to slow mass transport and specialized process design, are less an issue here.

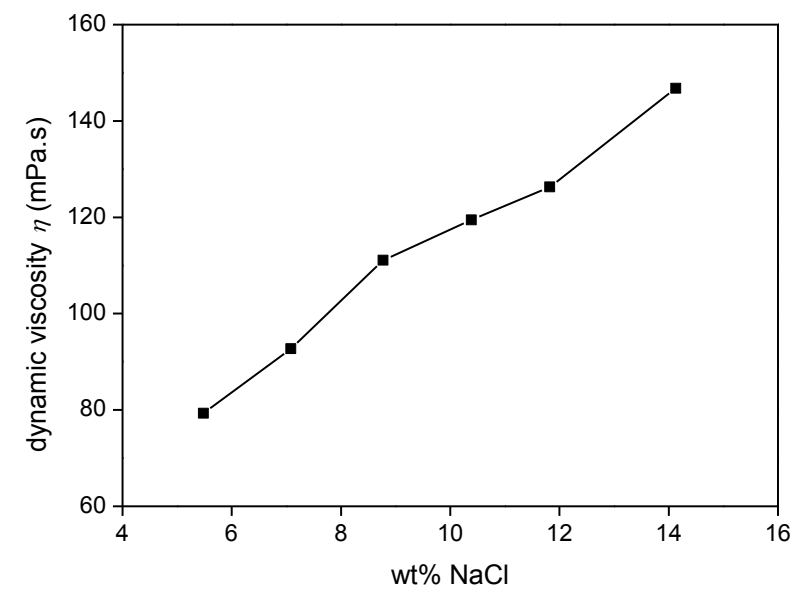

Figure 3. Dynamic viscosity at room temperature $\left(22^{\circ} \mathrm{C}\right)$ of the IL-rich phase after extraction as a function of the wt\% of $\mathrm{NaCl}$ in the extraction mixture, $[\mathrm{Co}(\mathrm{II})]=1.5 \mathrm{~g} \cdot \mathrm{kg}^{-1},[\mathrm{Ni}(\mathrm{II})]=1.5 \mathrm{~g} \cdot \mathrm{kg}^{-1}$, $\left[\mathrm{P}_{44414}\right][\mathrm{Cl}]=40 \mathrm{wt} \%$, all calculated over the entire mixture.

In conclusion, this Communication demonstrates that the ILABS-HLLE system based on $\left[\mathrm{P}_{44414}\right][\mathrm{Cl}]$ and $\mathrm{NaCl}$ shows enhanced properties compared to conventional IL solvent extraction systems. The IL used in our system is fluorine-free and such ionic liquids are generally considered to be cheaper and more environmentally friendly than ILs containing fluorinated anions. Furthermore, the loss of IL to the aqueous phase is limited, which makes the process economically and environmentally more interesting. In addition, the most important advantage is the potentially faster extraction kinetics by application of HLLE, combined with the much lower viscosity of the IL-rich phase compared to the Cyphos IL 101 system. The low viscosity is also advantageous for process design, because high viscosities would require special pumping systems. Finally, the $\mathrm{NaCl}$ that is added to the system is used more beneficially. In quaternary phosphonium chloride extraction systems, chloride anions need to be added to the aqueous phase anyway 
to achieve extraction to the IL phase. So the fact that it also induces phase separation of the hydrophilic IL means it is not required to work with a highly hydrophobic IL such as Cyphos IL 101. Nevertheless, the IL-ABS system described in this Communication still needs some improvement, including optimization of the composition of the mixture to increase the separation between $\mathrm{Co}(\mathrm{II})$ and $\mathrm{Ni}(\mathrm{II})$. Moreover, other hydrophilic ILs should be tested and compared to $\left[\mathrm{P}_{44414}\right][\mathrm{Cl}]$ and the IL-ABS-HLLE could also be applied to other metal ion separations and higher metal loadings.

This research was financially supported by the FWO-Flanders (research project G.0900.13), IWT-Flanders (PhD fellowship to BO) and KU Leuven (projects GOA/13/008 and IOF-KP RARE ${ }^{3}$ ). Support by IoLiTec (Heilbronn, Germany) is also gratefully acknowledged.

\section{Notes and references}

1 Z. Kolarik, Solvent Extr. Ion Exch., 2013, 31, 24-60.

2 F. Kubota and M. Goto, Solvent Extr. Res. Dev., Jpn., 2006, 13, 23-36.

3 I. Billard, A. Ouadi and C. Gaillard, Anal. Bioanal. Chem., 2011, 400, 1555-1566.

4 K. Binnemans, Chem. Rev., 2007, 107, 2592-2614.

5 J. F. Brennecke and E. J. Maginn, AIChE J., 2001, 47, 23842389.

6 R. D. Rogers and K. R. Seddon, Science, 2003, 302, 792-793.

7 K. R. Seddon, J. Chem. Technol. Biotechnol., 1997, 68, 351356.

8 S. Wellens, R. Goovaerts, C. Moller, J. Luyten, B. Thijs and K. Binnemans, Green Chem., 2013, 15, 3160-3164.

9 B. Onghena, J. Jacobs, L. Van Meervelt and K. Binnemans, Dalton Trans., 2014, 43, 11566-11578.

10 T. Vander Hoogerstraete, B. Onghena and K. Binnemans, Int. J. Mol. Sc., 2013, 14, 21353-21377.

11 T. Vander Hoogerstraete, B. Onghena and K. Binnemans, J. Phys. Chem. Lett., 2013, 4, 1659-1663.

12 Y. Kohno, S. Saita, Y. J. Men, J. Y. Yuan and H. Ohno, Polym. Chem., 2015, 6, 2163-2178.

13 R. P. Swatloski, J. D. Holbrey and R. D. Rogers, Green Chem., 2003, 5, 361-363.

14 D. Depuydt, L. Liu, C. Glorieux, W. Dehaen and K. Binnemans, Chem. Commun., 2015, DOI: 10.1039/C5CC05649G.

15 R. F. M. Frade and C. A. M. Afonso, Hum. Exp. Toxicol., 2010, 29, 1038-1054.

16 D. Zhao, Y. Liao and Z. Zhang, CLEAN - Soil, Air, Water, 2007, 35, 42-48.

17 M. G. Freire, A. F. M. Claudio, J. M. M. Araujo, J. A. P. Coutinho, I. M. Marrucho, J. N. C. Lopes and L. P. N. Rebelo, Chem. Soc. Rev., 2012, 41, 4966-4995.

18 N. J. Bridges and R. D. Rogers, Sep. Sci. Technol., 2008, 43, 1083-1090.

19 K. E. Gutowski, G. A. Broker, H. D. Willauer, J. G. Huddleston, R. P. Swatloski, J. D. Holbrey and R. D. Rogers, J. Am. Chem. Soc., 2003, 125, 6632-6633.
20 M. Dilip, N. J. Bridges, H. Rodriguez, J. F. B. Pereira and R. D. Rogers, J. Solution Chem., 2015, 44, 454-468.

21 Y. Pei, J. Wang, L. Liu, K. Wu and Y. Zhao, J. Chem. Eng. Data, 2007, 52, 2026-2031.

22 A. E. Visser, S. T. Griffin, D. H. Hartman and R. D. Rogers, J. Chromatogr. B, 2000, 743, 107-114.

23 M. S. Alvarez, E. Gutierrez, A. Rodriguez, M. A. Sanroman and F. J. Deive, Ind. Eng. Chem. Res., 2014, 53, 8615-8620.

24 Y. Akama, M. Ito and S. Tanaka, Talanta, 2000, 53, 645-650.

25 R. D. Rogers, A. E. Visser, R. P. Swatloski, D. H. Hartman and S. T. Griffin, Abstr. Pap. Am. Chem. Soc., 1999, 217, U897U897.

26 D. Dupont, D. Depuydt and K. Binnemans, J. Phys. Chem. B, 2015, 119, 6747-6757.

27 S. Wellens, B. Thijs and K. Binnemans, Green Chem., 2012, 14, 1657-1665.

28 T. Vander Hoogerstraete, S. Wellens, K. Verachtert and K. Binnemans, Green Chem., 2013, 15, 919-927.

29 B. K. Tait, Hydrometallurgy, 1993, 32, 365-372.

30 M. Matsumoto, A. Panigrahi, Y. Murakami and K. Kondo, Membranes, 2011, 1, 98-108.

31 M. Atanassova, V. Mazan and I. Billard, ChemPhysChem, 2015, 16, 1703-1711.

32 B. Onghena and K. Binnemans, Ind. Eng. Chem. Res., 2015, 54, 1887-1898. 